\title{
Manganese toxicity in the central nervous system: Decreeing of catecholamine in rat's brains
}

\author{
Vahid Yousefi Babadi ${ }^{1}$, Leyla Sadeghi ${ }^{2}$, Esmaiel Amraie ${ }^{3}$, Mohammad Rezaei $^{4}$, \\ Ali Akbar Malekirad ${ }^{5}$, Meghdad Abarghouei Nejad ${ }^{1^{*}}$ \\ ${ }^{1}$ Department of Biology, Faculty of Sciences, Payam Noor University, Iran; \\ *Corresponding Author: Meghdad.abarghouei.nejad@gmail.com \\ ${ }^{2}$ Department of Biochemistry, Faculty of Biological Science, Tarbiat Modares University, Tehran, Iran \\ ${ }^{3}$ Physiology Research Center, Isfahan Cardiovascular Research Center, Isfahan Cardiovascular Research Institute, Isfahan University \\ of Medical Sciences, Isfahan, Iran \\ ${ }^{4}$ Department of Food Safety and Hygiene, School of Public Health, Tehran University of Medical Sciences, Tehran, Iran \\ ${ }^{5}$ Payam Noor University, Iran
}

Received 4 November 2013; revised 5 December 2013; accepted 16 December 2013

Copyright (C) 2013 Vahid Yousefi Babadi et al. This is an open access article distributed under the Creative Commons Attribution License, which permits unrestricted use, distribution, and reproduction in any medium, provided the original work is properly cited.

\begin{abstract}
Manganese is an essential metal in human that functions in many enzymes. In contrast excessive exposure to Mn results in neurotoxicity. Accumulation of manganese damages central nervous system and causes Parkinson disease like syndrome called manganism. Mn neurotoxicity has been suggested to involve an imbalance in catecholamine neurotransmitters. It hypothesized that Mn can obstruct catecholamine synthesis pathway by inhibition of Tyrosine hydroxylase. Previous studies demonstrated that chronic and acute dose of Mn has different possible effects on catecholamine synthesis. It's assumed that an acute dose of manganese can kill dopaminergic cells. Therefore, we focused the effect of $\mathrm{Mn}$ in catecholamine concentration on the rat's brain by $\mathrm{MnCl}_{2}$ injection intraperitoneally and analyzed their brains after the time interval. This study used different acute doses in short time courses and different chronic doses at different exposing times to investigate which of them (exposing dose or time) is more important in $\mathrm{Mn}$ toxic effect. Measurement of catecholamine concentration performed by fluorescence assay in acidic and oxidant environment.
\end{abstract}

Keywords: Manganese; Neurotoxicity; Catecholamine; Toxicology

\section{INTRODUCTION}

Manganese makes up about $0.10 \%$ of the earth's crust and is the 12th most abundant element, but in the cell it is the second most abundant element [1,2]. However, manganese is an essential trace element and normally occurs at low concentrations. It involved as an activator or cofactor with a number of diverse enzymes involved with energy metabolism, digestion, and lipid and protein metabolism. In the living system manganese does not undergo metabolism; it is absorbed and excreted unchanged [3]. Manganese affects the tightly controlled balance of neurotransmitters production, metabolism and release, so manganese hemostasis is essential for brain functions $[4,5]$.

Manganese is used in the production of dyes, fertilizers, fungicides, paints, lacquers, glazes, dry batteries, fireworks and rubber and wood preservatives. Occupational exposure to manganese occurs mainly in the mining and processing of manganese ores, alloys and steel during welding [6]. Accumulation of manganese in the central nervous system following an intraperitoneal or intramuscular injection occurs slowly reaching a maximum in about 30 days [7]. Manganese also is transported to organs rich in mitochondria (in particular the liver, pancreas, and pituitary) where it is rapidly concentrated [8].

Central nervous system is an important target for manganese poisoning and accumulation of $\mathrm{Mn}$ in the CNS triggers neurotoxicity resulting in a neurological brain disorder, referred to as manganism that mostly shoed in miners $[9,10]$. Initial manifestations of $\mathrm{Mn}$ intoxication included slowing motor functions, compulsive behavior, emotional instability, intellectual and memory impairment [11-13]. Excessive brain manganese precipitation shares multiple features with Parkinson's disease $[5,9,14]$. Distribution of $\mathrm{Mn}$ is homogeneous in the brain 
with lower concentrations in the spinal cord. The average turnover time in the central nervous system is reported to be about 110 days following intraperitoneal injection and about 55 days for intramuscular injection [7].

One of the toxic effects of the manganese is associated with disruption of the glutamine (Gln)/glutamate (Glu)caminobutyric acid (GABA) cycle (GGC) between astrocytes and neurons, thus leading to changes in Gluergic and/or GABAergic transmission and Gln metabolism [10]. $\mathrm{Mn}$ in the 3+ oxidation state Mn complexes with transferrin ( $\mathrm{Tf}$ ) and, in a similar manner to iron ( $\mathrm{Fe})$, is transported by a $\mathrm{Tf}$ receptor-mediated mechanism [4], so other toxic effects are related to competition of $\mathrm{Mn}$ whit $\mathrm{Zn}, \mathrm{Fe}$ and $\mathrm{Mg}$ in joining to transferring [15]. But the most important $\mathrm{Mn}$ toxicity is decreasing of nourotransmitersand cathecolamins in the CNS that affected body movment and intelligent [9].

There are many studies that investigate poisoning effect of $\mathrm{Mn}$ on the living systems $[6,9,10]$. Aschnerand et al. discussed about the mechanisms of dopaminergic neuronal toxicity in C. elegans and demonstrated potential role of $\mathrm{Mn}$ in dopaminergic degeneration [4]. Guilarte worked on non-human primate model of Mn neurotoxicity suggests that $\mathrm{Mn}$ decreases dopamine release in the brain [5]. Dr. Racette demonstrates a unique pattern of dopaminergic dysfunction in active welders with chronic exposure to Mn containing welding fumes [16]. Finally, Dydak et al. presented novel magnetic resonance (MR) spectroscopy data in Mn exposed smelter workers and demonstrated abnormalities in the thalamus and frontal cortex for those workers [16].

In vitro, astrocytic cultures are highly sensitive to $\mathrm{Mn}$ and undergo apoptotic cell death secondary to mitochondrial dysfunction [17]. Mn preferentially and rapidly enters the mitochondrial matrix via the calciumuniporter [18].

Depletion of dopamine in nigrostriatal neurons has been so documented during Mn exposure that it causes injury in CNS [19-21]. Tyrosine hydroxylase (TH) is a rate limiting enzyme in the biosynthesis of catecholamine and catalyzes the first step of a biochemical synthetic pathway in which L-tyrosine is converted to L3,4dihydroxy-phenylalanine (L-dopa). Recent studies reported that $\mathrm{PKC} \delta$ negatively regulates $\mathrm{TH}$ activity and dopamine synthesis by enhancing PP2A activity in dopaminergic neurons [22].

This study focuses on the effect of intranasal manganese administration on brain catecholamines in two acute and chronic doses and different time courses in rats. The $\mathrm{MnCl}_{2}$ was chosen as it is water soluble and is distributed more rapidly to the tissues than the water insoluble forms and it can be transported across synapses [23]. Catecholamines converted to the fluorescent in the presence of oxidant agents and in acidic medium. Manganese chloride injected intraperitoneally and brain's catecholamine concentration measured in different time intervals.

\section{MATERIALS AND METHODS}

\subsection{Animals}

The animals used in this study were male wistar rats at the age of approximately 35 days and weight of about 250 - 300 grams which were provided from the lab animal center of, payam-e-noor University. The rats are kept in special cages and have been provided by the necessary amount of food and water. Their care situations included room temperature of $23-25$ centigrade degree with the humidity of $55 \%-60 \%$ and the light period was divided into 12 hours of light and 12 hours of darkness. Then they are divided into 8 groups of 6 rats in each. Control group: In these groups the care situations were similar to the other groups with the difference that the intra-peritoneal injection of Manganese chloride was not done and these groups injected by physiological serum. Three groups undergoes acute dose of $\mathrm{MnCl}_{2}$ in 2 days that injection was done daily (Group 1 with the dosage of $15 \mathrm{mg} / \mathrm{kg}$, group 2 with the dosage of $10 \mathrm{mg} / \mathrm{kg}$ and one control group that injected daily by $0.2 \mathrm{ml}$ physiological serum).

Five group injected daily by chronic dose $(2 \mathrm{mg} / \mathrm{kg})$ in different time courses (group 1: 15 days, group 2: 30 days, group 3: 45 days, group 4: 60 days) and one control group for chronic dose (group 5). $\mathrm{MnCl}_{2}$ injection was done intraperitoneally and daily by defined doses. After ascertained time intervals rats killed by standard method and their brains used for catecholamine concentration measurement.

\subsection{Sample Preparation and Fluorescence Measurements}

24 hours after last injection rats killed and its brain separated. Fresh brains or brains that had been frozen in liquid nitrogen and stored at $-75^{\circ} \mathrm{C}$ were homogenized in cold $0.05 \mathrm{~N} \mathrm{HClO} 4$ containing dihydroxybenzylamine as internal standard [24]. The supernate following centrifugation at $12,000 \times \mathrm{g}$ for 15 minutes was processed according to Felice et al., except that $0.1 \mathrm{~N} \mathrm{HClO}_{4}$ was required to elute the amines from the alumina [25].

Catecholamine concentration measurement done by fluorescence spectroscopy. Catecholaminein alkaline environment and in the presence of ascorbic acid and iodine as a strong oxidant agent convert to fluorescent substance [26]. Fluorescence studies were carried out on a Perkin Elmer luminescence spectrometer LS 55. The excitation wavelength was set at $405 \mathrm{~nm}$ and the emission spectra were recorded in $515 \mathrm{~nm}$. Excitation and emission slit were both set at $5 \mathrm{~nm}$. 


\subsection{Statistical Analysis}

For data analysis SPSS10 software was used and in order to specify the difference between the experimental and control groups the T-Test was performed. Difference in the level $\mathrm{P}<0.05$ was considered significant.

\section{RESULTS}

This study for investigation of Mn effect on catecholamine concentration used from rats that injected by $\mathrm{MnCl}_{2}$ solution in different concentrations and time intervals $[9,10]$. In section 1 of study we used acute concentration of $\mathrm{MnCl}_{2}$ (10 and $\left.15 \mathrm{mg} / \mathrm{kg}\right)$ in only 2 days. As Table 1, result showed in presence of $\mathrm{MnCl}_{2}$ catecholamine concentration showed significant decreasing and in $15 \mathrm{mg} / \mathrm{kg}$ dose decreasing is more distinguished (amount of 101 for $15 \mathrm{mg} / \mathrm{kg}$ injection in comparison of 941 for control group).

Section 2 of this study is investigation of chronic dose of $\mathrm{MnCl}_{2}$ in catecholamine concentration but in longer intervals. Result showed when time of experiment was longer (so espousing time is longer) catecholamine concentration more affected and more decreased. This amount for 60 days experimental group was 501 rather than control that is 901 (Figure 1). And rats in longer time periods group more showed more significant decrease in comparison of control group (Table 2).

\section{DISCUSSION}

Manganese is one of the essential elements for animals and human but exposing of animals and human to high concentration of Mn cause accumulation of this element in CNS that occurs in miner, welders, ferroalloy workers,

Table 1. Catecholamine concentration differences in presence of acute dose of $\mathrm{Mn}$ in short time (2 days).

\begin{tabular}{cc}
\hline Rat groups & Catecholamine concentration \\
\hline Control & $941 \pm 23$ \\
Acute dose $(15 \mathrm{mg} / \mathrm{Kg})$ & $101 \pm 23$ \\
Acute dose $(10 \mathrm{mg} / \mathrm{Kg})$ & $26 \pm 2$ \\
\hline
\end{tabular}

Table 2. Catecholamine concentration variations in presence of chronic dose of $\mathrm{Mn}$ in the different and long time intervals.

\begin{tabular}{cc}
\hline Catecholamine concentration & Rat groups \\
\hline $901 \pm 23$ & Control \\
$751 \pm 23$ & Chronic dose in 15 days \\
$584 \pm 12$ & Chronic dose in 30 days \\
$524 \pm 29$ & Chronic dose in 45 days \\
$501 \pm 21$ & Chronic dose in 60 days
\end{tabular}

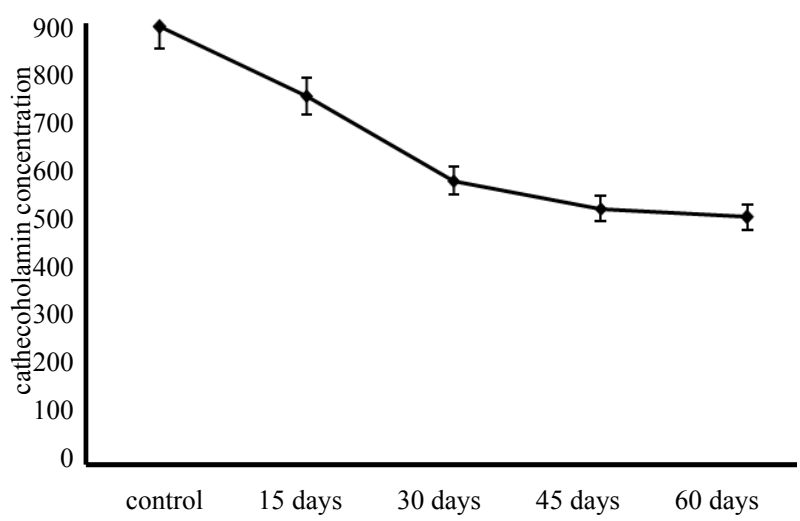

Figure 1. decreasing of catecholamine in time intervals. This decrease is not linear and body can resilient against Mn toxic effect at long exposing time.

battery manufacturers and car mechanics. Manganism, the poisoning effect of $\mathrm{Mn}$, is neurological brain disorder that involved CNS. Previous studies showed one of the important effects of exposing to $\mathrm{Mn}$ is loosing of the neurotransmitters that cause neurodegenerative symptoms $[6,9] . \mathrm{Mn}$ in chronic dose caused activation of $\mathrm{PKC} \delta$ that negatively regulates $\mathrm{TH}$ activity and dopamine synthesis by enhancing PP2A activity in dopaminergic neurons [22]. This study also confirmed previous resultsand results showed exposing of rats to $\mathrm{Mn}$ caused decreased catecholamine, it is may be because of tyrosine hydroxylase (TH) inhibition, $\mathrm{TH}$ is rate limiting enzyme in catecholamine synthesis [9].

$\mathrm{Mn}$ in acute dose cause cell death, it activated caspase3-mediated proteolytic activation of the proapoptotic kinase $\mathrm{PKC} \delta$ plays a role in Mn-induced apoptosis in N27 mesencephalic dopaminergic cells [9,27]. In this study, when acute dose of Mn used in experiment whit short time duration (only 2 day) catecholamine concentration showed significant decrease. Decreasing of catecholamine concentration in acute dose and short term is more than chronic dose and long term, so dose of this neurotoxic element is more important rather than exposing time. It's may be because of increased damaged dopaminergic cells [27]. Comparison of second stage results implicated that whit linear increasing of exposing time, catecholamine concentration doesn't decrease linearly because whit duplication of exposing time catecholamine concentration doesn't showed half amount in result, so neurotoxic effects of $\mathrm{Mn}$ is dose dependent rather than time dependent.

\section{CONCLUSION}

Results showed when exposing time increased, reduction of catecholamine concentration increased and was more affected. It is may be because of tyrosine hydroxylase $(\mathrm{TH})$ inhibition, $\mathrm{TH}$ is rate limiting enzyme in cate- 
cholamine synthesis.

\section{REFERENCES}

[1] Holleman, A.F., Wiberg, E. and Wiberg, N. (1995) Lehrbuch der anorganischen Chemie. Walter de Gruyter.

[2] Romani, A. (2007) Magnesium homeostasis in mammalian cells. Frontiers in Bioscience, 12, 308-331. http://dx.doi.org/10.2741/2066

[3] Orten, J.M. and Neuhaus, O.W. (1975) Human biochemistry. CV Mosby.

[4] Aschner, M. and Aschner, J.L. (1991) Manganese neurotoxicity: Cellular effects and blood-brain barrier transport. Neuroscience \& Biobehavioral Reviews, 15, 333-340. http://dx.doi.org/10.1016/S0149-7634(05)80026-0

[5] Guilarte, T.R. (2010) Manganese and Parkinson's disease: A critical review and new findings. Environmental Health Perspectives, 118, 1071.

http://dx.doi.org/10.1289/ehp.0901748

[6] Blecharz-Klin, K., et al. (2012) Effect of intranasal manganese administration on neurotransmission and spatial learning in rats. Toxicology and Applied Pharmacology, 265, 1-9. http://dx.doi.org/10.1016/j.taap.2012.09.015

[7] Stokinger, H. (1981) The metals. In: Patty's Industrial Hygiene and Toxicology, 2, 1749-1769.

[8] Deng, Q., et al. (2013) Interaction of occupational manganese exposure and alcohol drinking aggravates the increase of liver enzyme concentrations from a cross-sectional study in China. Environmental Health, 12, 30. http://dx.doi.org/10.1186/1476-069X-12-30

[9] Zhang, D., et al. (2011) Effects of manganese on tyrosine hydroxylase $(\mathrm{TH})$ activity and $\mathrm{TH}-$ phosphorylation in a dopaminergic neural cell line. Toxicology and Applied Pharmacology, 254, 65-71. http://dx.doi.org/10.1016/j.taap.2010.03.023

[10] Sidoryk-Wegrzynowicz, M. and Aschner, M. (2013) Manganese toxicity in the central nervous system: The glutamine/glutamate-gamma-aminobutyric acid cycle. Journal of Internal Medicine, 273, 466-477. http://dx.doi.org/10.1111/joim.12040

[11] Barceloux, D.G. (1999) Manganese. Journal of Toxicology-Clinical Toxicology, 37, 293-307. http://dx.doi.org/10.1081/CLT-100102427

[12] Lee, J.-W. (2000) Manganese intoxication. Archives of Neurology, 57, 597. http://dx.doi.org/10.1001/archneur.57.4.597

[13] Lucchini, R., et al. (2012) Neurological impacts from inhalation of pollutants and the nose-brain connection. Neurotoxicology, 33, 838-841. http://dx.doi.org/10.1016/j.neuro.2011.12.001

[14] Aschner, M., et al. (2009) Manganese and its role in Parkinson's disease: From transport to neuropathology. Neuromolecular medicine, 11, 252-266. http://dx.doi.org/10.1007/s12017-009-8083-0

[15] Dodd, C., Bloomquist, J. and Klein, B. (2012) Consequences of manganese administration for striatal dopamine and motor behavior in 1-methyl-4-phenyl-1, 2, 3, 6-tetrahydropyridine-exposed C57BL/6 mice. Human \& Experimental Toxicology, 32, 865-880.

[16] Racette, B.A., et al. (2012) Pathophysiology of manganese-associated neurotoxicity. Neurotoxicology, 33, 881886. http://dx.doi.org/10.1016/j.neuro.2011.12.010

[17] Yin, Z., et al. (2008) Mitochondrial-dependent manganese neurotoxicity in rat primary astrocyte cultures. Brain Research, 1203, 1-11. http://dx.doi.org/10.1016/j.brainres.2008.01.079

[18] Gavin, C.E., Gunter, K.K. and Gunter, T.E. (1990) Manganese and calcium efflux kinetics in brain mitochondria. Relevance to manganese toxicity. Biochemical Journal, 266, 329-334.

[19] Guilarte, T.R., et al. (2008) Impairment of nigrostriatal dopamine neurotransmission by manganese is mediated by pre-synaptic mechanism(s): Implications to manganese-induced Parkinsonism. Journal of Neurochemistry, 107, 1236-1247. http://dx.doi.org/10.1111/j.1471-4159.2008.05695.x

[20] Erikson, K.M., et al. (2008) Duration of airborne-manganese exposure in rhesus monkeys is associated with brain regional changes in biomarkers of neurotoxicity. Neurotoxicology, 29, 377-385. http://dx.doi.org/10.1016/j.neuro.2007.12.007

[21] Aschner, M., Lukey, B. and Tremblay, A. (2006) The Manganese health research program (MHRP): Status report and future research needs and directions. Neurotoxicology, 27, 733-736. http://dx.doi.org/10.1016/j.neuro.2005.10.005

[22] Zhang, D., et al. (2007) Protein kinase $\mathrm{c} \delta$ negatively regulates tyrosine hydroxylase activity and dopamine synthesis by enhancing protein phosphatase-2a activity in dopaminergic neurons. The Journal of Neuroscience, 27, 5349-5362. http://dx.doi.org/10.1523/JNEUROSCI.4107-06.2007

[23] Takeda, A., et al. (1998) Manganese transport in the neural circuit of rat CNS. Brain research bulletin, 45, 149152. http://dx.doi.org/10.1016/S0361-9230(97)00330-4

[24] Latchoumycandane, C., et al. (2005) Protein kinase C $\delta$ is a key downstream mediator of manganese-induced apoptosis in dopaminergic neuronal cells. Journal of Pharmacology and Experimental Therapeutics, 313, 46-55. http://dx.doi.org/10.1124/jpet.104.078469

[25] Felice, L.J., Felice, J.D. and Kissinger, P.T. (1978) Determination of catecholamines in rat brain parts by reverse-phase ion-pair liquid chromatography. Journal of neurochemistry, 31, 1461-1465. http://dx.doi.org/10.1111/j.1471-4159.1978.tb06573.x

[26] Feller, D.J. and O’Dell, B.L. (1980) Dopamine and norepinephrine in discrete areas of the copper-deficient rat brain. Journal of Neurochemistry, 34, 1259-1263. http://dx.doi.org/10.1111/j.1471-4159.1980.tb09968.x

[27] Anton, A.H. and Sayre, D.F. (1964) The distribution of dopamine and dopa in various animals and a method for their determination in diverse biological material. Journal of Pharmacology and Experimental Therapeutics, 145, 326-336. 